\title{
STRUCTURAL STUDIES OF TRANSCRIPTIONAL REGULATION BY LySR-TYPE TRANSCRIPTIONAL REGULATORS IN BACTERIA
}

\author{
Maharani Pertiwi Koentjoro ${ }^{1}$ and Naoto Ogawa, ${ }^{1,2}$ \\ ${ }^{1}$ The United Graduate School of Agricultural Science, Gifu University, 1-1 Yanagido, Gifu-Shi, Gifu 501-1193, Japan. \\ ${ }^{2}$ Faculty of Agriculture, Shizuoka University, 836 Ohya, Suruga-ku, Shizuoka-Shi, Shizuoka 422-8529, Japan.
}

\begin{abstract}
LysR-type transcriptional regulators (LTTRs) comprise one of the largest families of transcriptional regulators in bacteria and control gene expression of various types of metabolic, virulence and physiological functions. LTTRs typically form homotetramers and require an inducer molecule(s) to activate the transcription of target genes. The N-terminal region of LTTRs contains a DNAbinding domain (DBD) with the winged helix-turn-helix motif that specifically binds the promoter region of target genes. The C-terminal region of LTTRs is connected to the DBD by a linker helix and forms the regulatory domain (RD) that contains a binding pocket for inducer molecules. Crystal structures of several LTTR family members together with their biochemical analyses have provided a potential mechanism for the initial process of transcriptional activation by LTTRs. First, helix $\alpha 3$ of the winged helix-turn-helix motif in DBD is supposed to distinguish the recognition binding site (RBS) in the promoter region, resulting in complex formation through interactions between two DBDs in the tetrameric LTTR and RBS. Formation of this complex seems to enable interactions between the other two DBDs in the LTTR tetramer and the activation binding site (ABS) in the promoter region. The binding of the tetrameric LTTR to both the RBS and ABS causes the promoter DNA to adopt a bent structure because the four DBDs in the tetrameric LTTR are arranged in a V-shaped manner at the bottom of the LTTR. Interaction of an inducer molecule(s) with the RD seems to cause a quaternary structural change of the LTTR that relaxes the bending angle of the promoter DNA with a concomitant shift of the bound DBDs at the ABS. These events facilitate recruitment of RNA polymerase to its binding site in the promoter region, which overlaps with the ABS for LTTR.
\end{abstract}

Keywords: Bacteria, chlorocatechol, LysR-type transcriptional regulator, transcription

\section{Introduction}

LysR-type transcriptional regulators (LTTRs) represent one of the largest families of prokaryotic transcriptional regulators (Henikoff et al., 1988), and functional orthologues are also found in archaea (Sun and Klein, 2004) and in chloroplast of a red alga (Minoda et al., 2010). LTTRs regulate transcription of genes that code for proteins that have diverse functions, including degradation of aromatic compounds, biosynthesis of amino acids, synthesis of virulence factors, $\mathrm{CO}_{2}$-fixation, $\mathrm{N}_{2}$-fixation, antibiotic resistance, cell division, quorum sensing and oxidative stress responses (reviewed in Maddocks and Oyston, 2008 and Schell, 1993). Table 1 shows several examples of LTTRs to show the variety of the function of the regulated genes.

LTTRs were initially defined in 1988 by Henikoff et al. They found primary structure similarities in bacterial transcription proteins, AmpR, LeuO, LysR, IlvY, CysB, NodD, MetR and $\mathrm{TfdO}$, and designated these proteins as LysR family members. LTTRs typically consist of $\sim 300$ amino acids and bind their target promoters as homotetramers (Akakura and Winans, 2002b; Feng et al., 2003). An LTTR located on the promoter must bind to an inducer molecule(s) to activate transcription. Some LTTRs are known to be present as a dimer or octamer (Parsek et al., 1994; Sainsbury et al., 2009); however, these examples are relatively rare. Primary sequence analysis and biochemical studies suggest 


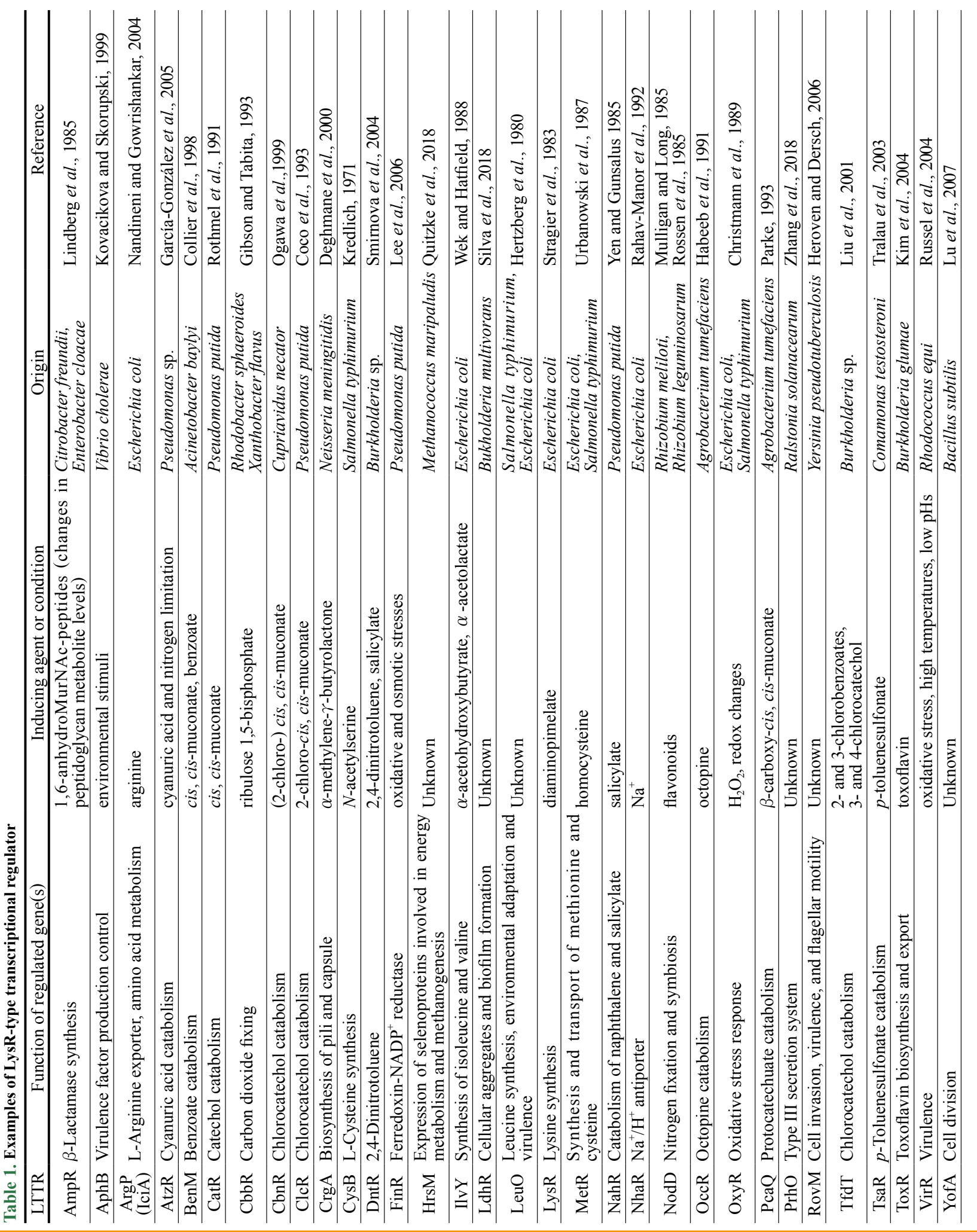


Please cite this article as

Koentjoro and Ogawa, Reviews in Agricultural Science, 6:105-118, 2018

http://dx.doi.org/10.7831/ras.6.105

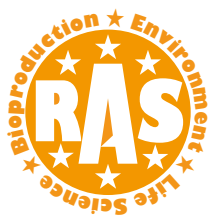

that LTTRs are composed of two domains: a DNA binding domain (DBD) and a regulatory domain (RD) (Schell, 1993).

DNase I footprinting analyses have revealed that LTTRs bind to an approximately $60 \mathrm{bp}$ region of the promoter DNA corresponding to $c a .-80$ to -20 upstream of the transcriptional start site in the absence of the inducer (Fig. 1) (Wek and Hatfield, 1988; Fisher and Long, 1989; Ogawa et al., 1999). The binding region of the promoter can be divided into two parts: the recognition binding site (RBS) and activation binding site (ABS). The RBS has an inverted repeat structure and two inverted repeat sequences are interrupted by several nucleotides (Huang and Schell, 1991; Toledano et al., 1994; Porrúa et al., 2010, MacLean et al., 2011). DNA sequence comparison of various promoters for LTTRs revealed a consensus sequence of RBS, the $\mathrm{T}-\mathrm{N}_{11}-\mathrm{A}$ motif (Figs. 1 and 2). The region of $\sim 60$ bp covered by LTTRs in the promoter containing presumably the RBS and ABS has been confirmed for the following examples: IlvY (Wek and Hatfield, 1988), NodD (Fisher and Long, 1989), OxyR (Storz et al., 1990; Toledano et al., 1994; Kullik et al., 1995a), NahR (Huang and Schell, 1991), OccR (Wang et al., 1992; Akakura and Winans, 2002b), CatR (Parsek et al., 1994), ClcR (McFall et al., 1997b), GcvA (Jourdan and Stauffer, 1998), CbnR (Ogawa et al., 1999), AphB (Kovacikova and Skorupski, 2001), CysB (Lochowska et al., 2004), YtxR (Axler-DiPerte et al., 2006), ArgP (Laishram and Gowrishankar, 2007; Minh et al., 2018), AtzR (Porrúa et al., 2007), PcaQ (MacLean et al., 2008), ToxR (Kim et al., 2009), NAC (Rosario et al., 2010) and ThnR (Rivas-Marín et al., 2016). Gel mobility shift and DNase I footprinting results indicate that LTTRs form stronger interactions with the RBS than with the ABS (MacLean et al., 2008; Porrúa et al., 2010). Although LTTRs interact weakly with the ABS, this site is essential for transcriptional activation (Tover et al., 2000; Porrúa et al., 2010). In the ABS, the binding site of an LTTR shifts from site-1 to site-2 upon inducer binding (or upon receiving an environmental signal) (Bundy et al.,
2002; McFall, et al., 1997b; Devesse et al., 2011; Porrúa et al., 2013). Binding of an LTTR to promoter DNA causes DNA bending, whose angle is generally relaxed when an inducer molecule(s) binds to the LTTR. After relaxation of this DNA bending, RNA polymerase seems to be recruited to the promoter site to activate transcription.

Since the molecular mechanism of transcriptional activation remains a central issue in biology, many studies have been performed in the field of LTTRs. Although full details of the transcription activation mechanism by LTTRs remains elusive, crystal structures of LTTRs and biochemical studies on the basis of the crystal structures have revealed parts of the transcription activation mechanism by LTTRs. In this review, we have summarized studies of LTTRs on the basis of their tertiary structures.

\section{CbnR: one of the representative models for LTTRs}

CbnR is a member of the LTTR family (Ogawa and Miyashita, 1999; Ogawa et al., 1999) and one of the best-characterized LTTRs. In 1999, Ogawa et al. identified CbnR as a positive regulator for $c b n A B C D$ genes (Ogawa et al., 1999) in Cupriavidus necator NH9. cbnABCD genes encode a series of enzymes involved in the ortho-cleavage pathway of chlorocatechols. CbnR forms a tetramer in solution and interacts with the RBS and ABS in the $c b n A$ promoter region. cis, cis-Muconate or 2-chlorocis, cis-muconate serves as an inducer of CbnR. In the $c b n A$ promoter region, the RBS spans the region -76 to -49 upstream of the transcription start site of the cbnA gene (Fig. 1). The RBS is presumed to be necessary for anchoring CbnR to the promoter region with its 5 bp inverted repeats (TIACG- $\left.\mathrm{N}_{5}-\mathrm{CGTA} A\right)(\mathrm{N}$ : nucleotide). The inverted repeats of RBS in the $c b n A$ promoter contain the consensus $\mathrm{T}-\mathrm{N}_{11}-\mathrm{A}$ motif for LTTRs (the conserved $\mathrm{T}$ and $\mathrm{A}$ are underlined in the above sentence). The ABS spans the region -44 to -19 upstream of the transcription start site of the cbn $A$ gene and overlaps with the -35 and -10 elements, which are

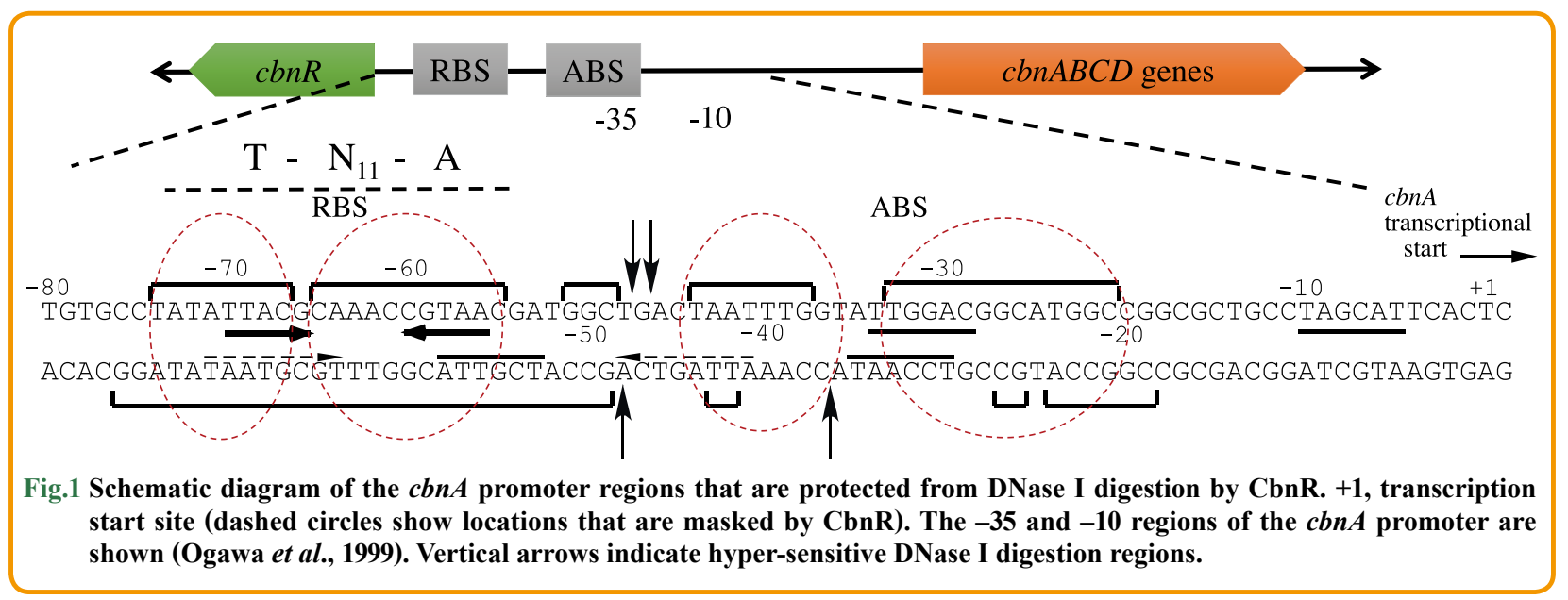




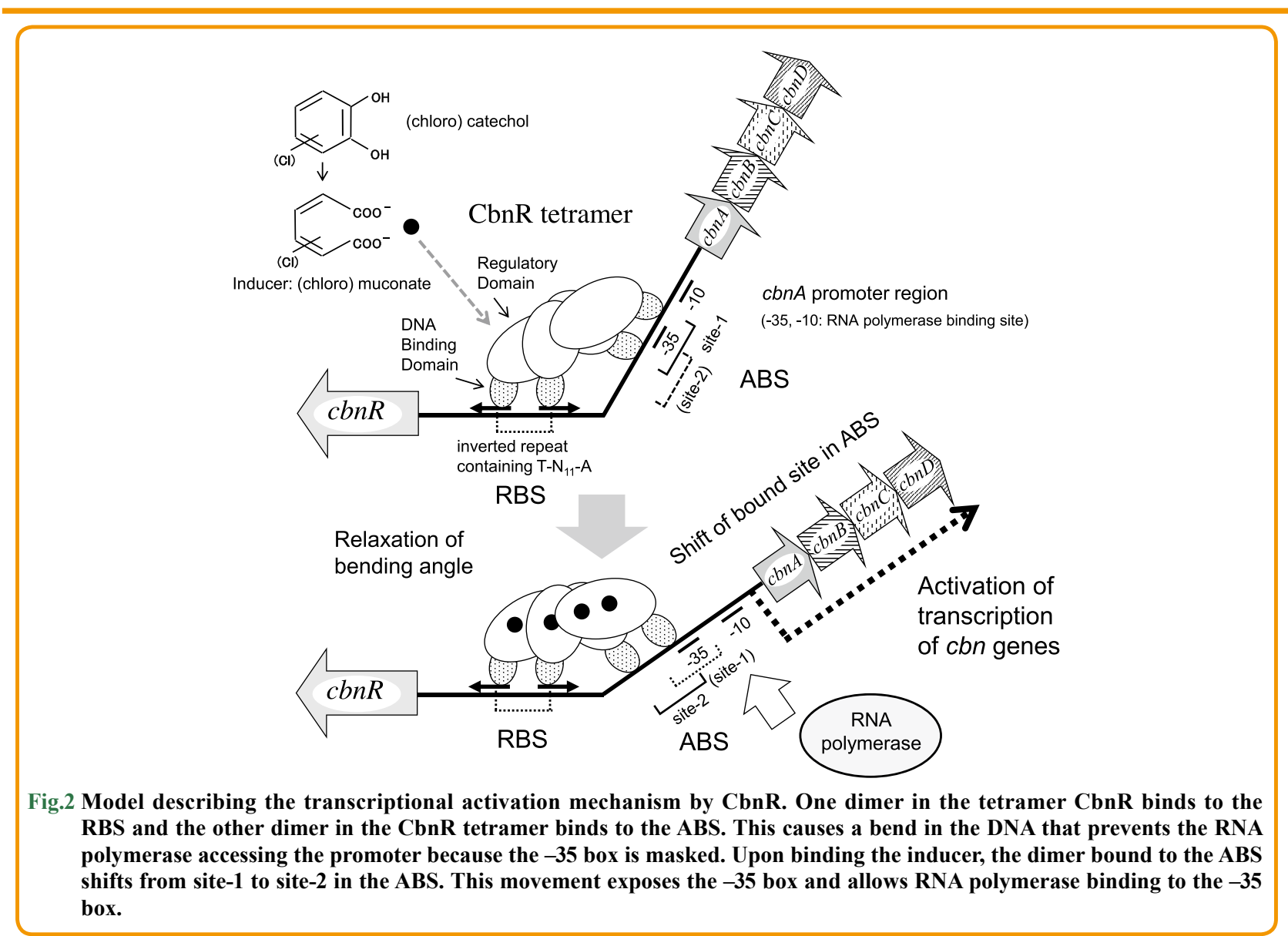

RNA polymerase binding sites (Fig. 1). Notably, binding of CbnR to both the ABS and RBS of the $c b n A$ promoter is likely to cause a bending of the promoter DNA by $78^{\circ}$. The binding angle was estimated by circular permutation gel shift analysis. Upon inducer binding, the bend angle is relaxed to $54^{\circ}$. While similar degrees of bend angles and relaxation upon inducer binding have been reported for other LTTR-binding promoter regions (McFall et al., 1997a; van Keulen et al., 1998; Minh et al., 2018), analysis of the tetrameric DntR by small angle X-ray scattering (SAXS) suggests that the bend angles obtained by circular permutation gel shift results could be underestimates (Lerche et al., 2016). Considering biochemical analyses of other LTTRs, the relaxation of the bend angle in the CbnR-DNA complex might be accompanied with a shift of CbnR binding in the ABS (Fig. 2) (Ogawa et al., 1999). Although such a shift of the binding site in ABS was not observed for the CbnR system, we presume this shift takes place because it has been observed in other LTTRs (Ogawa et al., 1999).

CbnR is the first example for which the crystal structure of a full-length LTTR was determined (Muraoka et al., 2003).
Therefore, CbnR has been a representative model to study the molecular mechanism of transcription activation by LTTRs. Mutational analyses of CbnR was performed on the basis of its crystal structure (Moriuchi et al. 2017). Furthermore, the crystal structure of the DBD of CbnR (hereafter CbnR(DBD)) in complex with promoter DNA has been determined (Koentjoro et al., 2018). The crystal structure of the CbnR(DBD)-DNA complex revealed the molecular mechanism of the sequence specificity of CbnR (Koentjoro et al., 2018). In this report, we frequently use the crystal structure of CbnR as a representative model of LTTRs.

\section{Overall and subunit structures of CbnR and other LTTRs}

The first tertiary structure describing structural features of an LTTR was the crystal structure of the RD of CysB (hereafter CysB(RD)) (Tyrrell et al., 1997). The CysB(RD) structure is a homodimer and each domain is composed of two subdomains. The crystal structure of $\mathrm{CysB}(\mathrm{RD})$ provides information about the inducer binding site. Although the crystal structure of $\mathrm{CysB}(\mathrm{RD})$ provided a valuable structural base for biochemical analysis of LTTRs, 
Please cite this article as

Koentjoro and Ogawa, Reviews in Agricultural Science, 6:105-118, 2018

http://dx.doi.org/10.7831/ras.6.105

several questions remained unanswered: (1) the arrangement of the four subunits in the tetrameric LTTRs; (2) the mechanism of DNA bending by an LTTR upon interaction with the promoter DNA; (3) the mechanism of specific interactions between an LTTR and the RBS/ABS; (4) the mechanism of the conformational change of the $\mathrm{RD}$ upon inducer binding; and (5) the quaternary structural changes of the LTTR upon inducer binding. These are critical questions for understanding the functional mechanism(s) of LTTRs. Some of these questions have been answered using structural information of LTTRs obtained after the CbnR structure was solved, whereas some of these questions remain elusive.

The first crystal structure of a full-length LTTR was determined for CbnR (Muraoka et al., 2003). Full-length CbnR forms a tetramer in the crystalline state (Fig. 3(A)). Since several biochemical studies showed that LTTRs are typically homotetramers in solution (Bundy et al., 2002; Jovanovic et al., 2003; Jang et al., 2018), the tetrameric structure of $\mathrm{CbnR}$ represents a model quaternary structure of various LTTRs. The quaternary structure of tetrameric $\mathrm{CbnR}$ is unique among tetrameric proteins; the tetramer of $\mathrm{CbnR}$ does not have the 222 point group symmetry, which is a typical point group found in tetrameric proteins. In $\mathrm{CbnR}$, the four subunits in the tetramer do not have the same conformation but adopt two distinct conformations, compact and extended forms (Fig. 3(B)). The CbnR tetramer can be described as a dimer of dimers that assembles via two distinct dimerization interfaces (Muraoka et al., 2003; Ezezika et al., 2007b; Monferrer et al., 2010; Devesse et al., 2011; Jo et al., 2015). The first dimer interface is located between two linker helices (residues 59-89; see below). This interaction forms a DBD dimer, in which two DBDs are related by a local two-fold axis. In the DBD dimer, one subunit adopts the compact conformation, whereas the other dimer adopts the extended conformation. The second interface is located between RDs (Fig. 3(A)). The interaction between two RDs makes a dimer of RDs, resulting in the formation of a dimer of the DBD dimers (tetrameric CbnR). This unique architecture of CbnR is shared among other tetrameric LTTRs. BenM, TsaR, DntR and OxyR were found to form essentially the same tetramer in the crystalline state (Ruangprasert et al., 2010; Monferrer et al., 2010; Devesse et al., 2011; Jo et al., 2015). Four DBDs in the tetrameric CbnR arrange in a V-shape at the bottom of the CbnR tetramer (Fig. 3(A)). This likely explains the DNA bending observed in the CbnR-promoter DNA complex. Interestingly, CrgA adopts a homo-octamer (Sainsbury et al., 2009) with the RDs forming a dimer interface of the dimeric CrgA. MetR, CatR, IlvY and NodD3 have also been identified as dimers in solution by biochemical analysis (Maxon et al., 1990; Parsek et al., 1994; Fisher and Long, 1993; Bender, 1991).

The crystal structure of CbnR revealed that the subunits of CbnR are composed of two domains and one linker helix (Fig. 4). Residues $1-58$ of CbnR forms the DBD, which has a winged helix-turn-helix (wHTH) motif. The linker helix (residues 59-89) connects the DBD to the RD and RD is composed of residues 90 291 (Fig. 4). RD is responsible for interactions between subunits as demonstrated in the crystal structure of $\mathrm{CysB}(\mathrm{RD})$ and is likely to be involved in the recognition of the inducer (Muraoka et al., 2003; Dangel et al., 2015; Ruangprasert et al., 2010).

Several crystal structures of full-length LTTRs have also been reported, namely AphB (PDB ID: 3T1B), ArgP (PDB ID: 3ISP), BenM (PDB ID: 3K1N), CrgA (PDB ID: 3HHG), DntR (PDB ID: 5AE5), MetR (PDB ID: 4AB6), OxyR (PDB ID: 4X6G) and TsaR (PDB ID: 3FXQ). These structures confirmed that the crystal structure of CbnR is a representative of the tetrameric LTTRs.

\subsection{Structure of the DNA binding domain $(D B D)$}

The DBD shares high amino acid sequence similarity for proteins that are members of the LTTR family (Fig. 5) (Schell 1993). Functional roles of amino acids involved in DNA binding have been analyzed by mutations of NahR (Schell and Sukhordhaman, 1989), OxyR (Kullik et al., 1995b; Zaim and Kierzek, 2003), GcvA (Jourdan and Stauffer, 1998), CysB (Lochowska et al., 2001), CrgA (Deghmane and Taha, 2003), OxyS (Li and He, 2012) and CbnR (Moriuchi et al, 2017). The DBD of LTTRs contains three helices $(\alpha 1, \alpha 2$ and $\alpha 3)$ and two $\beta$-strands and adopts the socalled wHTH motif (Muraoka et al., 2003; Sainsbury et al., 2010; Monferrer et al., 2010; Zhou et al., 2010; Lerche et al., 2016). The $\alpha$ 3 helix is referred to as the recognition helix because it recognizes specific DNA sequences by inserting into the major groove of the DNA. A deep cleft forms between the $\alpha 1$ and $\alpha 3$ helices, which is a favored structural feature to facilitate packing into DNA via hydrophobic interactions (Alanazi et al., 2013; Koentjoro et al., 2018). Two wHTH motifs from the DBD dimer bind to pseudo twofold symmetric DNA operator sequences such that each monomer recognizes a half site (Laishram and Gowrishankar, 2007; Alanazi et al., 2013; Koentjoro et al., 2018).

\subsection{Interaction between $\operatorname{LTTR}(D B D)$ and promoter $D N A$}

Details of the DBD-DNA interaction have been analyzed using crystal structures of LTTR DBDs in complex with their target DNA. High sequence similarities of the amino acid sequences of the DBDs of LTTRs and the promoter DNA sequences suggest a conserved mechanism of promoter DNA recognition by the DBDs of LTTRs. Nonetheless, variation in the amino acid sequences of the DBDs of LTTRs appears to be required for recognition of distinct DNA promoter sequences (MacLean et al., 2008; Lönneborg and Brzezinski, 2011). Currently, crystal structures of BenM(DBD)-DNA and CbnR(DBD)-DNA complexes have been determined (Fig. 6). Comparative analysis of these crystal structures revealed several differences between CbnR(DBD) and 


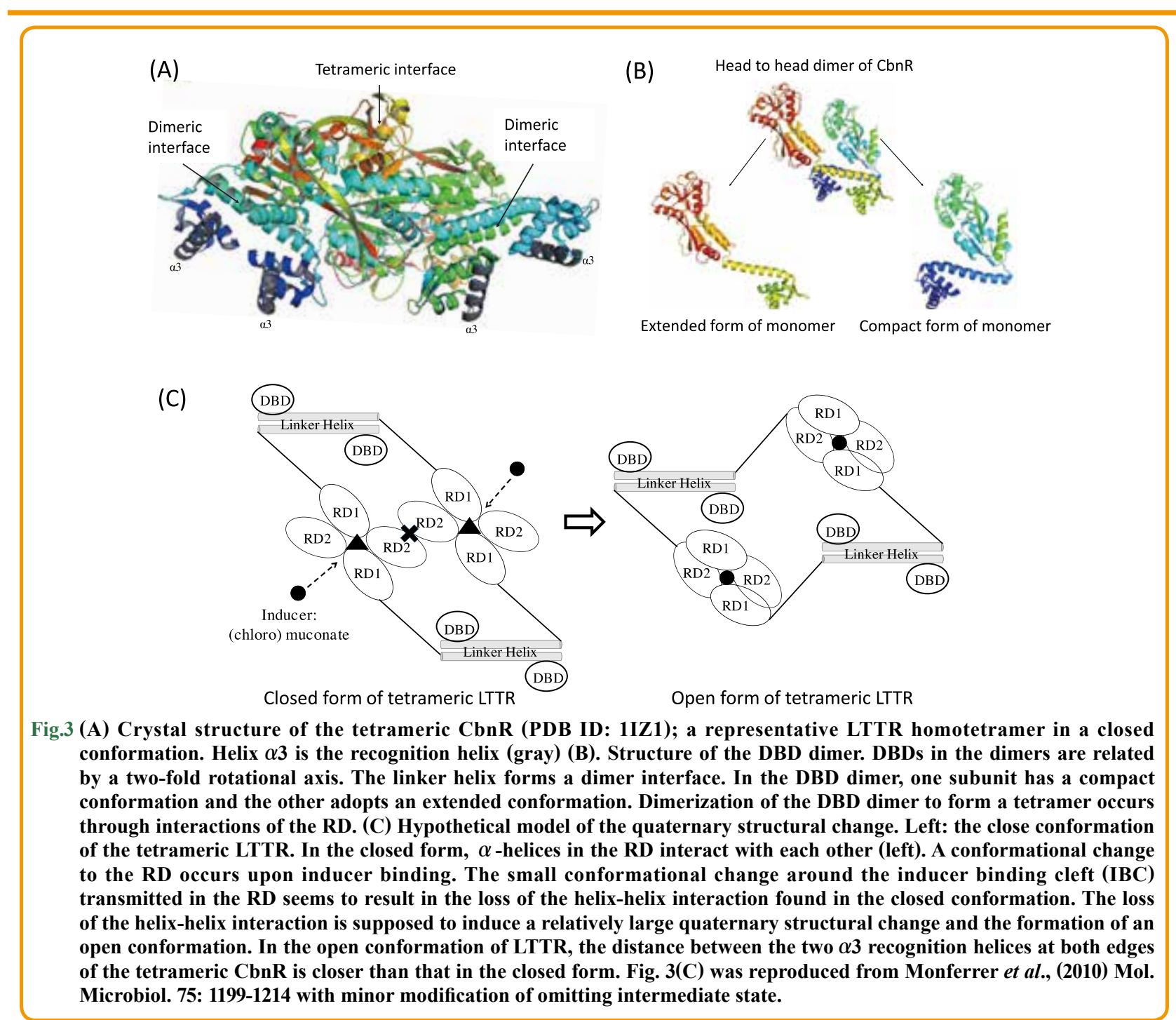

BenM(DBD) in the interaction with their specific DNA sequences. The overall structures of the two complexes were, however, found to be quite similar. In addition, three nucleotides out of four in each of the inverted repeat sequences are conserved between RBSs for CbnR and BenM; the nucleotide sequence of the inverted repeats of the RBS for CbnR is TTAC- $\mathrm{N}_{7}-$ GTAA and that for BenM is ATAC- $\mathrm{N}_{7}-$ GTAT (the conserved T and A for most LTTRregulated promoters are underlined, and differences in the two inverted repeats are shown in bold type). Despite these similarities in the DBD and RBS, CbnR could not bind to the RBS recognized by BenM. Surprisingly, a single amino acid difference at residue 33, Thr33 in CbnR and Ser33 in BenM, explains their promoter sequence selectivity on the basis of the crystal structures of the complexes of DBD and DNA (Koentjoro et al., 2018).
Interaction between the DBD and DNA was analyzed by mutations of the DBD and the promoter sequence. Interestingly, the length of the spacer sequence between the RBS and ABS affect the DNA binding activity of the LTTR in the absence of an inducer. Normally, the spacer length between the RBS and ABS is 3-6 bp (Sainsbury et al., 2009; Li and He, 2012). Analysis by deletion and insertion of nucleotides in the spacer region revealed that the distance between the RBS and ABS is critical to the strength of the interaction with tetrameric LTTRs (Tover et al., 2000; Minh et al., 2018). ArgP is a LTTR protein that regulates arginine transport in Escherichia coli and is essential for transcriptional activation of the $\arg O$ promoter (Zhou et al., 2010). Increasing the length of the spacer sequence between the RBS and ABS of the $\arg O$ promoter region resulted in a deficiency of transcription of $\operatorname{argO}$ (Minh et al., 

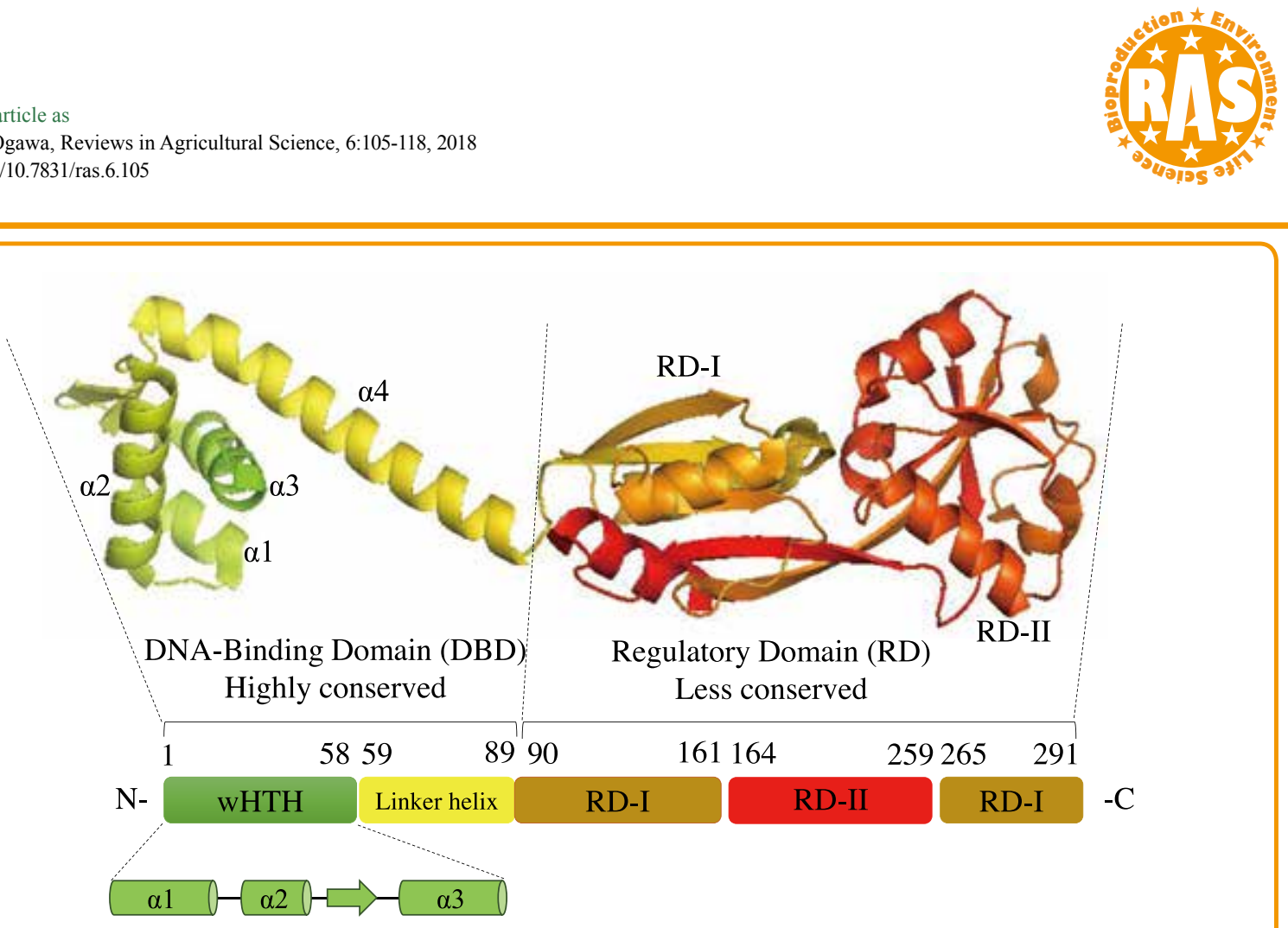

Fig.4 Structure of the CbnR subunit (PDB ID: 1IZ1). A cartoon model (top) and schematic drawing presenting the domain composition (bottom) are shown. The CbnR subunit is composed of the DNA binding domain (DBD) with the winged helix-turn-helix motif, the linker helix that is involved in dimerization, and the regulatory domain (RD) that has an inducer binding site

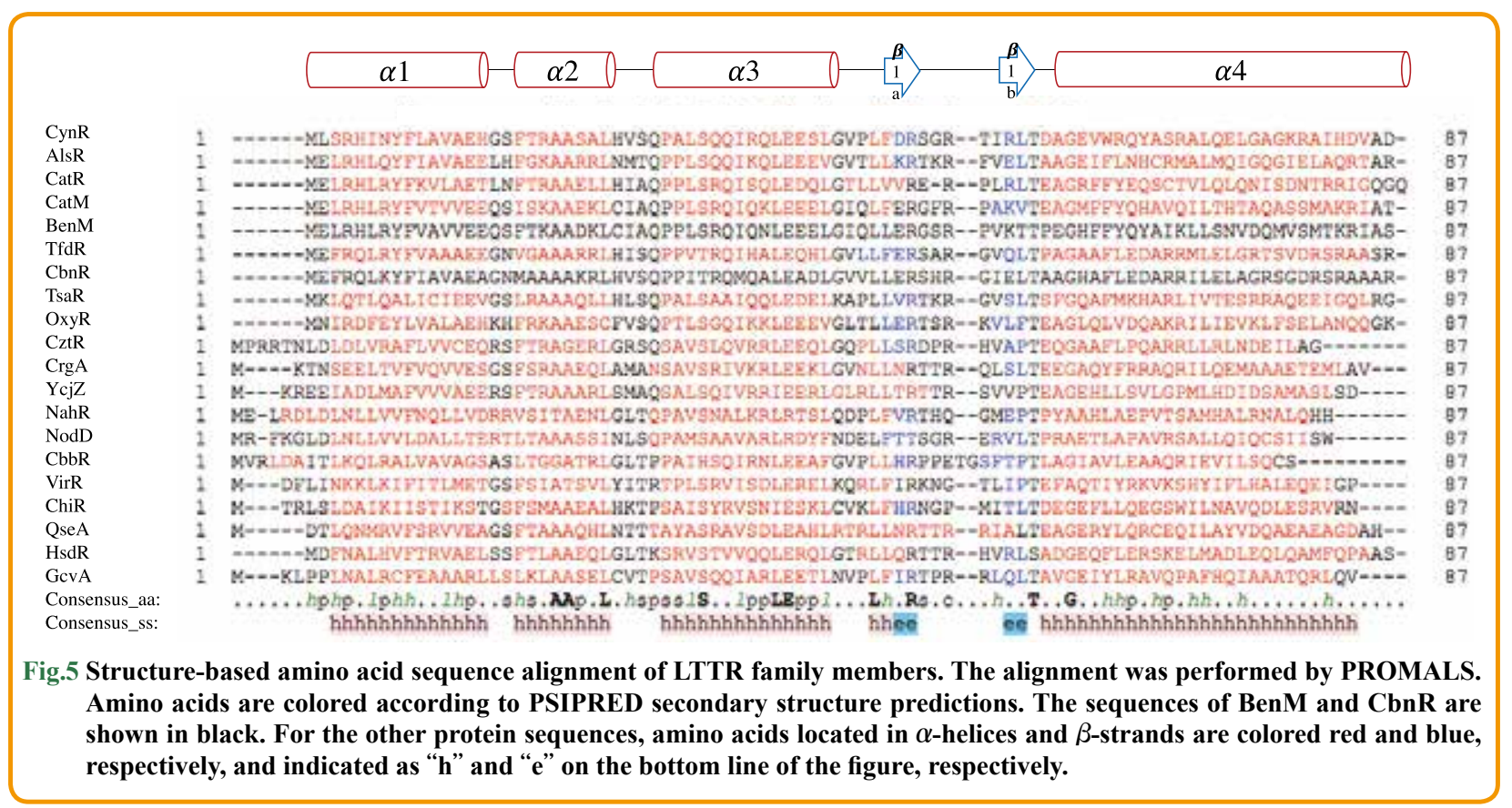




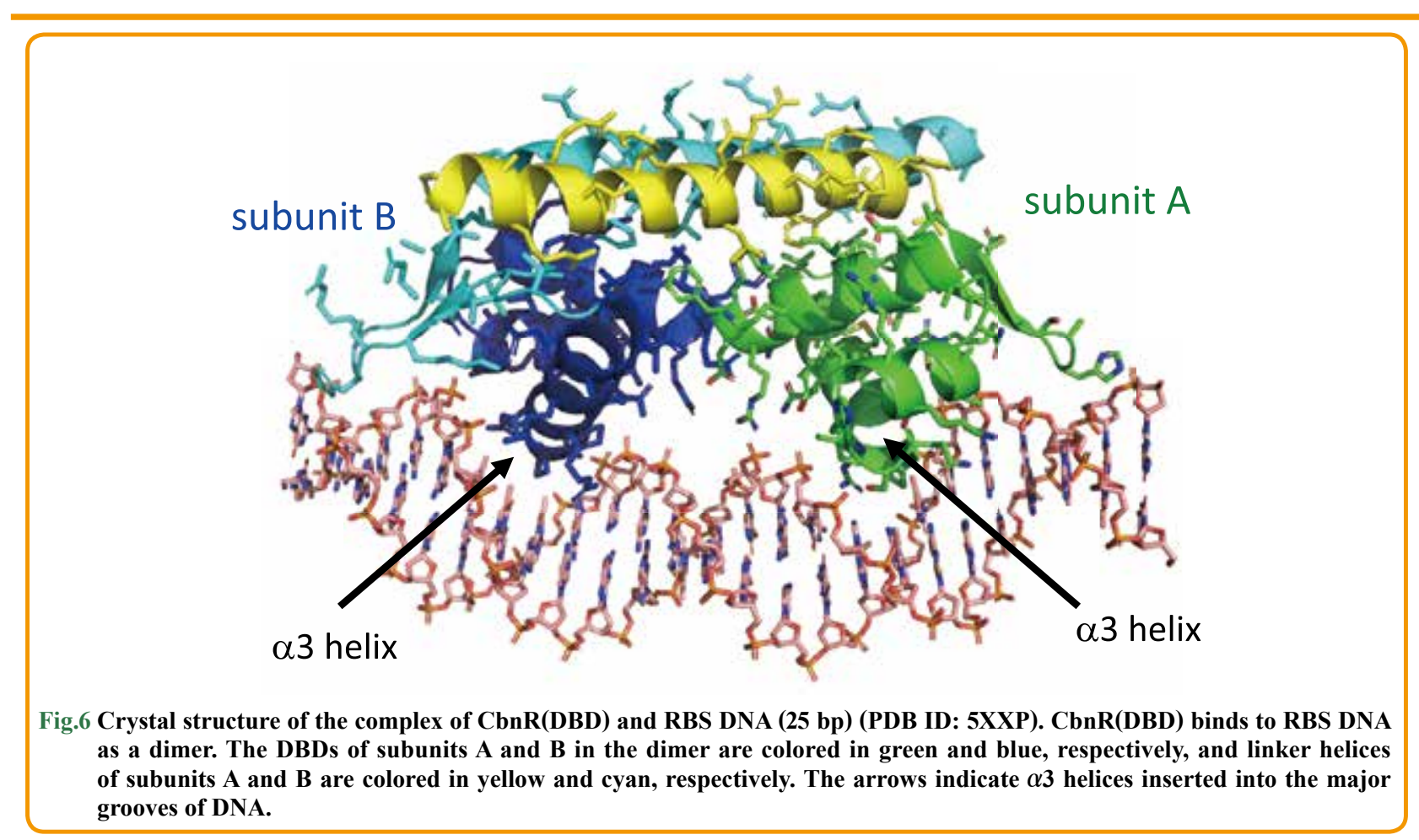

2018). Thus, the distance between the RBS and ABS is likely to be critical for transcription activity.

\subsection{Regulatory domain ( $R D$ )}

The RD of LTTRs has an inducer binding cavity (IBC) and is presumed to play a critical role in the conformational change of the LTTR tetramer upon inducer binding (Choi et al., 2001; Maddocks and Oyston, 2008; Quade et al., 2011; Park et al., 2017). The RD from CysB was the first crystal structure solved of a RD (Tyrell et al., 1997). Subsequently, crystal structures of RDs of LTTR family members with inducer molecules bound (or adopting an inducing state conformation) have been reported. These include OxyR (Choi et al., 2001; Jo et al., 2015), DntR (Smirnova et al., 2004; Lerche et al., 2016), BenM and CatM (Ezezika et al., 2007a; Craven et al., 2009) and TsaR (Monferrer 2010). The RD is composed of two subdomains, RD-I and RD-II. The two subdomains are connected by two crossovers that form the IBC. RD-I consists of a five-stranded $\beta$-sheet with three $\alpha$-helices surrounding this $\beta$-sheet structure. RDII contains a five-stranded $\beta$-sheet that is strongly twisted and four $\alpha$ -helices (Fig. 4) (Tyrell et al., 1997; Muraoka et al., 2003; Monferrer et al., 2010; Quade et al., 2011; Park et al., 2017). Structural studies of BenM, OxyR, PcaQ, RovM, AphB and DntR have led us to hypothesize that inducer binding (or environmental change) to the RD of LTTR causes a conformational change in the RD that is propagated throughout the tetrameric LTTR and changes the bend angle of the promoter DNA (Kovacikova and Skorupski, 2001; Bundy et al., 2002; Smirnova et al., 2004; Quade et al., 2011; Wei et al., 2012; Jo et al., 2015) However, while crystal structures of OxyR (Choi et al., 2001; Jo et al., 2015), BenM (Ezezika et al., 2007a) and DntR (Devesse et al., 2011) have revealed conformational changes of the RD upon inducer binding, conformational changes of tetrameric full-length LTTR upon inducer binding have not been observed in the crystal.

The functional significance of the RD was also analyzed by mutation analysis (Kullik et al., 1995a; Cebolla et al., 1997; Lochowska et al., 2001; Akakura and Winans, 2002a; Dangel et al., 2005; Craven et al., 2009; Lang and Ogawa, 2009; Taylor et al., 2012). For example, our group performed a mutational study using CbnR (Moriuchi et al., 2017). Of the eight mutations to CbnR(RD), three mutations (Phe98Ala, Lys129Ala and Phe202Ala) appear to directly affect inducer binding, and this observation is corroborated by a study of BenM, in which the corresponding residues are known to interact with the cognate inducer molecule (Ezezika et al., 2007a). Interestingly, we obtained two constitutive active mutants, Arg199Ala and Val246Ala, which activated transcription without the inducer. The amino acid exchanges in these mutants appear to induce a structural change that mimics the change caused by inducer binding. These results indicate that conformational changes in the RD are important in activating transcription. 
Please cite this article as

Koentjoro and Ogawa, Reviews in Agricultural Science, 6:105-118, 2018

http://dx.doi.org/10.7831/ras.6.105

\subsection{Transition from closed to open form of tetrameric LTTRs}

Protein-protein interactions are important for the assembly of tetrameric LTTRs (Bundy et al., 2002; Ezezika et al., 2007b; Sainsbury et al., 2009; Knapp and Hu, 2010; Ruangprasert et al., 2010; Devesse et al., 2011). Residues located at the interface regions of RDs (Fig. 3(A)) are responsible for the formation of tetramers. In particular, interactions between two DBD dimers are critical for formation of the tetramer (Muraoka et al., 2003; Ezezika et al., 2007b; Ruangprasert et al., 2010).

Although no quaternary structural changes of LTTRs upon binding an inducer have been observed in crystal structures, some crystal structures of LTTRs suggest a transition of the quaternary structure of tetrameric LTTR from a closed to open form upon binding an inducer (Monferrer et al., 2010; Lerche et al., 2016). In the closed form, there are interactions between two $\alpha$ helices from two RD-II subdomains (two $\alpha \mathrm{V}$ helices from two distinct RDII) that are related by a two-fold axis. Upon inducer binding, local conformational changes in the RD (Ezezika et al., 2007a; Devesse et al., 2011; Park et al., 2017) seem to disrupt helix-helix interactions leading to a structural change to the open form (Fig. 3(C)) (Choi et al., 2001; Monferrer et al., 2010; Devesse et al., 2011). This conformational change could possibly be mediated by the flexibility of the RD. These changes appear to occur in TsaR (Monferrer et al., 2010), ArgP (Zhou et al., 2010) and DntR (Devesse et al., 2011). These conformational changes are supposed to cause a shift of the binding site in ABS, resulting in productive contact of LTTR with the $\alpha$ C-terminal domain ( $\alpha$-CTD) of RNA polymerase on the promoter (Chugani et al., 1997; Fritsch et al., 2000; Lochowska et al., 2004).

Since there are helix-helix interactions ( $\alpha \mathrm{V}-\alpha \mathrm{V}$ interactions) between two RD-II subdomains in the tetrameric CbnR (Fig. 3(C), left panel), the crystal structure of CbnR can be considered to be a closed form. In contrast, as there are no corresponding helixhelix interactions in tetrameric TsaR, the structure of TsaR is an open form. Thus, the tetrameric CbnR is assumed to represent an inducer-free non-activating state, whereas tetrameric TsaR is an active state (Monferrer et al., 2010). Notably, a SAXS experiment successfully observed a corresponding change of the quaternary structure of DntR between the inducer-free and inducer-bound states (Lerche et al., 2016).

4. Sliding dimer model for transcriptional activation of LTTR

The sliding dimer model has been proposed to explain the scheme of transcriptional activation by LTTR (van Keulen et al., 2003; Porrúa et al., 2007; Monferrer et al., 2010; Lerche et al., 2016). Transcriptional activation by LTTR should begin with interactions with the RBS using two $\alpha 3$ helices in a DBD dimer of the tetrameric LTTR. After the LTTR-RBS interaction, the other DBD dimer in LTTR should bind the ABS (Sainsbury et al., 2009;
Ruangprasert et al., 2010; Zhou et al., 2010; Alanazi et al., 2013; Rivas-Marín et al., 2016) to form the tetrameric LTTR-DNA complex. The order of binding, from RBS to ABS, is reasonable because the affinity between the DBD and RBS is significantly stronger than that between the DBD and ABS. Since the four DBDs in the LTTR tetramer arrange in a V-shape manner, it is reasonable to postulate that the interaction between tetrameric LTTR and promoter DNA causes bending of the DNA in accordance with the arrangement of the four DBDs. This LTTRDNA complex without inducer is considered to be a resting state and seem to adopt the closed form of the tetrameric LTTR.

Inducer molecule binding to the IBC in the RD seem to trigger a quaternary structural change of the LTTR tetramer (Fig. $3(\mathrm{C})$ ), resulting in the open form of the tetrameric LTTR on the promoter. The change in the quaternary structure of tetrameric LTTR is proposed to result in the rearrangement of the DBDs, leading to a relaxation of DNA bending. In this process, DBDs interacting with the ABS shift on the promoter and change the interacting site from site- 1 to site- 2 of the ABS (Fig. 2). Since site1 of the ABS overlaps with the -35 box of the promoter, the shift of the binding site exposes the -35 box to enable RNA polymerase binding (Monferrer et al., 2010; Ruangprasert et al., 2010; Devesse et al., 2011). The change of the ABS recognition site has been demonstrated in studies of OxyR (Toledano et al., 1994), OccR (Wang et al., 1992), ClcR (McFall et al., 1997b) AtzR (Porrúa et al., 2010) and DntR (Lerche et al., 2016). In the sliding dimer mechanism, the change of the angle of bent DNA accompanied with a quaternary structural change of the tetrameric LTTR would be a critical step. After release of the -35 box for RNA polymerase binding, a complex involving LTTR, sigma factor and RNA polymerase would form on the promoter to initiate transcription.

\section{Conclusions}

In this review, we discussed how tertiary structures of LTTRs have provided valuable insight into the interaction of LTTRs with promoter DNA and aided our understanding of the mechanism of the initial step of transcriptional activation by LTTRs. Initiation of transcriptional activation is a multistep process that consists of a series of conformational changes of LTTRs, promoter DNA and their complexes. Although structural and biochemical analyses have revealed that relaxation of DNA bending and a shift of the binding site on the ABS are critical steps for recruiting RNA polymerase to the promoter DNA, other important features of initiation of transcriptional activation remain poorly understood. Details of the quaternary structural changes of LTTRs upon inducer binding and structural details describing relaxation of the DNA bending angle can be analyzed with high-resolution tertiary structures. Furthermore, the molecular 
mechanism of transcriptional initiation is a critical question that could be answered based on the tertiary structure of the initiation complex. For future tertiary structure analysis, not only X-ray crystallography but also cryo-electron microscopy will play an important role. These are challenging structural problems that will be tackled in the near future.

\section{ACKNOWLEDGMENTS}

MPK thanks the Japanese government (MEXT) for the award of a Monbukagakusho scholarship for studying in Japan. We thank Prof. Toshiya Senda for critical reading of the manuscript and assistance in the preparation of the revised version of the review.

\section{REFERENCES}

Akakura R and Winans (2002a) Constitutive mutations of the OccR regulatory protein affect DNA bending in response to metabolites released from plant tumors. J. Biol. Chem., 277: 5866-5874.

Akakura $\mathrm{R}$ and Winans (2002b) Mutations in the $o c c Q$ operator that decrease OccR-induced DNA bending do not cause constitutive promoter activity. J. Biol. Chem., 277: 15773-15780.

Alanazi AM, Neidle EL and Momany C (2013) The DNA-binding domain of BenM reveals the structural basis for the recognition of a $\mathrm{T}-\mathrm{N}_{11}-\mathrm{A}$ sequence motif by LysR-type transcriptional regulators. Acta Crystallograph. Sect. D Biol. Cryst., 69: 1995-2007.

Axler-DiPerte GL, Miller VL, and Darwin AJ (2006) YtxR, a conserved LysR-like regulator that induces expression of genes encoding a putative ADP-ribosyltransferase toxin homologue in Yersinia enterocolitica. J. Bacteriol., 188: 8033-8044.

Bender RA (1991) The role of the NAC protein in the nitrogen regulation of Klebsiella aerogenes. Mol. Microbiol., 5: 2575-2580.

Bundy BM, Collier LS, Hoover TR and Neidle EL (2002) Synergistic transcriptional activation by one regulatory protein in response to two metabolites. Proc. Natl. Acad. Sci. USA, 99: 7693-7698.

Cebolla A, Sousa C and de Lorenzo V (1997) Effector specificity mutants of the transcriptional activator NahR of naphthalene degrading Pseudomonas define protein sites involved in binding of aromatic inducers. J. Biol. Chem., 272: 3986-3992.

Christman MF, Storz G and Ames BN (1989) OxyR, a positive regulator of hydrogen peroxide-inducible genes in Escherichia coli and Salmonella typhimurium, is homologous to a family of bacterial regulatory proteins. Proc. Natl. Acad. Sci. USA, 86: 3484-3488.

Choi HJ, Kim SJ, Mukhopadhyay P, Cho S, Woo JR, Storz G, and Ryu SE (2001) Structural basis of the redox switch in the OxyR transcription factor. Cell, 105: 103-113.

Chugani SA, Parsek MR, Hershberger CD, Murakami K, Ishihama A and Chakrabarty AM (1997) Activation of the catBCA promoter: Probing the interaction of CatR and RNA polymerase through in vitro transcription. J. Bacteriol., 179: 2221-2227.

Coco WM, Rothmel RK, Henikoff S, and Chakrabarty AM (1993) Nucleotide sequence and initial functional characterization of the $c l c R$ gene encoding a LysR family activator of the $c l c A B D$ chlorocatechol operon in Pseudomonas putida. J. Bacteriol., 175: 417-427.

Collier LS Gaines GL 3rd and Neidle EL (1998) Regulation of benzoate degradation in Acinetobacter sp. strain ADP1 by BenM, a LysR-type transcriptional activator. J Bacteriol., 180: 2493-2501.

Craven, SH, Ezezika OC, Haddad S, Hall RA, Momany C and Neidle EL (2009) Inducer responses of BenM, a LysR-type transcriptional regulator from Acinetobacter baylyi ADP1. Mol Microbiol., 72: 881-894.

Dangel AW, Gibson JL, Janssen AP and Tabita FR (2005) Residues that influence in vivo and in vitro CbbR function in Rhodobacter sphaeroides and identification of a specific region critical for coinducer recognition. Mol. Microbiol., 57: 1397-1414.

Dangel AW and Tabita FR (2015) CbbR, the Master regulator for microbial carbon dioxide fixation. J. Bacteriol., 197: 3488-3498.

Deghmane AE, Petit S, Topilko A, Pereira Y, Giorgini D, Larribe M and Taha MK (2000) Intimate adhesion of Neisseria meningitidis to human epithelial cells is under the control of the $\operatorname{crg} A$ gene, a novel LysR-type transcriptional regulator. EMBO J., 19: 1068-1078.

Deghmane AE and Taha MK (2003) The Neisseria meningitidis adhesion regulatory protein $\mathrm{Crg} \mathrm{A}$ acts through oligomerization and interaction with RNA polymerase. Mol. Microbiol., 47: 135-143.

Devesse L, Smirnova I, Lönneborg R, Kapp U, Brzezinski P, Leonard GA and Dian C (2011) Crystal structures of DntR inducer binding domains in complex with salicylate offer insights into the activation of LysR-type transcriptional regulator. Mol. Microbiol., 8: 354-367.

Ezezika OC, Haddad S, Clark TJ, Neidle EL and Momany C (2007a) Distinct effector-binding sites enable synergistic transcriptional activation by BenM, a LysR-type regulator. J. Mol. Biol., 367:616-629.

Ezezika OC, Haddad S, Neidle EL and Momany C (2007b) Oligomerization of BenM, a LysR-type transcriptional regulator: Structural basis for the aggregation of proteins in this family. Acta Crystallograph. Sect. F Struct. Biol. Cryst. Commun., 63: 361-368.

Feng J, Li Q, Hu H-L, Chen X-C and Hong G-F (2003) Inactivation of the nod box distal half-site allows tetrameric NodD to activate $\operatorname{nod} A$ transcription in an inducer-independent manner. Nucleic Acids Res., 31: 3143-3156.

Fisher RF and Long SR (1989) DNA footprint analysis of the 
Please cite this article as

Koentjoro and Ogawa, Reviews in Agricultural Science, 6:105-118, 2018

http://dx.doi.org/10.7831/ras.6.105

transcriptional activator proteins NodD1 and NodD3 on inducible nod gene promoters. J. Bacteriol., 171: 5492-5502.

Fisher RF and Long SR (1993) Interactions of NodD at the nod box: NodD binds to two distinct sites on the same face of the helix and induces a bend in the DNA. J. Mol. Biol., 233: 336-348.

Fritsch PS, Urbanowski ML and Stauffer GV (2000) Role of the RNA polymerase $\alpha$ subunits in MetR-dependent activation of $m e t E$ and $m e t H$ : Important residues in the $\mathrm{C}$-terminal domain and orientation requirements within RNA polymerase. J. Bacteriol., 182: 5539-5550.

García-González V, Govantes F, Porrúa O, and Santero E (2005) Regulation of the Pseudomonas sp. strain ADP cyanuric acid degradation operon. J. Bacteriol., 187: 155-167.

Gibson JL and Tabita FR (1993) Nucleotide sequence and functional analysis of $c b b R$, a positive regulator of the Calvin cycle operons of Rhodobacter sphaeroides. J. Bacteriol., 175: 5778-5784.

Habeeb LF, Wang L and Winans SC (1991) Transcription of the octopine catabolism operon of the Agrobacterium tumorinducing plasmid pTiA6 is activated by a LysR-type regulatory protein. Mol Plant Microbe Interact., 4: 379-385.

Henikoff S, Haughn GW, Calvo JM and Wallace JC (1988) A large family of bacterial activator proteins. Proc. Natl. Acad. Sci. USA, 85: 6602-6606.

Heroven AK and Dersch P (2006) RovM, a novel LysR-type regulator of the virulence activator gene $\operatorname{rov} A$, controls cell invasion, virulence and motility of Yersinia pseudotuberculosis. Mol. Microbiol., 62: 1469-1483.

Hertzberg KM, Gemmill R, Jones J and Calvo JM (1980) Cloning of an EcoRI-generated fragment of the leucine operon of Salmonella typhimurium. Gene, 8:135-152.

Huang J and Schell MA (1991) In vivo interactions of the NahR transcriptional activator with its target sequences. J. Biol. Chem., 266: 10830-10838.

Jang Y, Choi G, Hong S, Jo I, Ahn J, Choi SH, and Ha NC (2018) A Novel tetrameric assembly configuration in VV2_1132, a LysR-type transcriptional regulator in Vibrio vulnificus. Mol. Cells, 41: 301-310.

Jo I, Chung IY, Bae HW, Kim JS, Song S, Cho YH and Ha NC (2015) Structural details of the OxyR peroxide-sensing mechanism. Proc. Natl. Acad. Sci. USA., 11: 6443-6448.

Jourdan AD and Stauffer GV (1998) Mutational analyses of the transcriptional regulator GcvA: Amino acids important for activation, repression, and DNA binding. J. Bacteriol., 180: 4865-4871.

Jovanovic M, Lilic M, Savic DJ and Jovanovic G (2003) The LysRtype transcriptional regulator CysB controls the repression of $h s l J$ transcription in Escherichia coli. Microbiology, 149: 3449-3459.

Kim J, Kim JG, Kang Y, Jang JY, Jog GJ, Lim JY, KimS, Suga
H, Nagamatsu T and Hwang I (2004) Quorum sensing and the LysR-type transcriptional activator ToxR regulate toxoflavin biosynthesis and transport in Burkholderia glumae. Mol. Microbiol., 54: 921-934.

Kim J, Oh J, Choi O, Kang Y, Kim H, Goo E, Ma J, Nagamatsu T, Moon JS, and Hwang I (2009) Biochemical evidence for ToxR and ToxJ binding to the tox operons of Burkholderia glumae and mutational analysis of ToxR. J. Bacteriol., 191: 4870-4878.

Knapp GS and Hu JC (2010) Specificity of the E. coli LysR-type transcriptional regulators. PLos ONE, 5: 1-4.

Koentjoro MP, Adachi N, Senda M, Ogawa N and Senda T. (2018) Crystal structure of the DNA-binding domain of the LysRtype transcriptional regulator CbnR in complex with a DNA fragment of the recognition-binding site in the promoter region. The FEBS J., 285: 977-989.

Kovacikova G and Skorupski K (1999) A Vibrio cholerae LysR homolog, AphB, cooperates with AphA at the tcpPH promoter to activate expression of the ToxR virulence cascade. J. Bacteriol., 181: 4250-4256.

Kovacikova G and Skorupski K (2001) Overlapping binding sites for the virulence gene regulators AphA, AphB and cAMP-CRP at the Vibrio cholerae tcpPH promoter. Mol. Microbiol., 41:393-407.

Kredich NM. (1971) Regulation of L-cysteine biosynthesis in Salmonella typhimurium. I. Effects of growth of varying sulfur sources and $O$-acetyl-L-serine on gene expression. J. Biol. Chem., 246:3474-3484.

Kullik I, Toledano MB, Tartaglia LA, and Storz G (1995a) Mutational analysis of the redox-sensitive transcriptional regulator OxyR: Regions important for oxidation and transcriptional activation. J. Bacteriol., 177: 1275-1284.

Kullik I, Stevens J, Toledano MB and Storz G (1995b) Mutational analysis of the redox-sensitive transcriptional regulator OxyR: Regions important for DNA binding and multimerization. J. Bacteriol., 177: 1285-1291.

Laishram RS and Gowrishankar J (2007) Environmental regulation operating at the promoter clearance step of bacterial transcription. Genes Dev., 21: 1258-1272.

Lang GH and Ogawa N (2009) Mutational analysis of the inducer recognition sites of the LysR-type transcriptional regulator TfdT of Burkholderia sp. NK8. Appl. Microbiol. Biotechnol., 83: 1085-1094.

Lee Y, Peña-Llopis S, Kang YS, Shin HD, Demple B, Madsen EL, Jeon CO, and Park W (2006) Expression analysis of the fpr (ferredoxin-NADP+ reductase) gene in Pseudomonas putida KT2440. Biochem. Biophys. Res. Commun., 339: 1246-1254.

Lerche M, Dian C, Round A, Lönneborg R, Brzezinski P and Leonard GA (2016) The solution configurations of inactive and activated DntR have implications for the sliding dimer 
mechanism of LysR transcription factors. Sci. Rep., 6: doi:10.1038/srep19988.

Li Y and He ZG (2012) The mycobacterial LysR-type regulator OxyS responds to oxidative stress and negatively regulates expression of the catalase-peroxidase gene. PLoS One, 7: doi. org/10.1371/journal.pone.0030186.

Lindberg F, Westman L and Normark S (1985) Regulatory components in Citrobacter freundii ampC $\beta$-lactamase induction. Proc. Natl. Acad. Sci. USA, 82: 4620-4624.

Liu S, Ogawa N and Miyashita K (2001) The chlorocatechol degradative genes, $t f d T-C D E F$, of Burkholderia sp. strain NK8 are involved in chlorobenzoate degradation and induced by chlorobenzoates and chlorocatechols Gene, 268: 207-214.

Lochowska A, Iwanicka-Nowicka, R, Plochocka D and Hryniewicz MM (2001) Functional dissection of the LysR-type CysB transcriptional regulator. J. Biol. Chem., 276: 2098-2107.

Lochowska A, Iwanicka-Nowicka R, Zaim J, WitkowskaZimny M, Bolewska K and Hryniewicz M (2004) Identification of activating region (AR) of Escherichia coli LysRtype transcription factor $\mathrm{CysB}$ and $\mathrm{CysB}$ contact site on RNA polymerase alpha subunit at the cys $P$ promoter. Mol. Microbiol., 53: 791-806.

Lönneborg R and Brzezinski P (2011) Factors that influence the response of the LysR type transcriptional regulators to aromatic compounds. BMC Biochem., 12: doi.org/10.1186/1471-2091-12-49.

Lu Z, Takeuchi M and Sato T (2007) The LysR-type transcriptional regulator YofA controls cell division through the regulation of expression of fts $W$ in Bacillus subtilis. J. Bacteriol., 189: 5642-5651.

MacLean AM, Anstey, MI and Finan TM (2008) Binding site determinants for the LysR-type transcriptional regulator PcaQ in the legume endosymbiont Sinorhizobium meliloti. J. Bacteriol., 190: 1237-1246.

MacLean AM, Haerty W, Golding BG and Finan TM (2011) The LysR-type PcaQ protein regulates expression of a protocatechuate-inducible ABC-type transport system in Sinorhizobium meliloti. Microbiology., 157: 2522-2533.

Maddocks SE and Oyston PCF (2008). Structure and function of the LysR-type transcriptional regulator (LTTR) family proteins. Microbiology, 154: 3609-3623.

Maxon ME, Wigboldus J, Brot N, and Weissbach H (1990) Structure-function studies on Escherichia coli MetR protein, a putative prokaryotic leucine zipper protein. Proc. Natl. Acad. Sci. USA., 87: 7076-7079.

McFall SM, Klem, TJ, Fujita, N, Ishihama, A, Chakrabarty, AM. (1997a) DNase I footprinting, DNA bending and in vitro transcription analyses of $\mathrm{ClcR}$ and $\mathrm{CatR}$ on the $c l c A B D$ promoter: evidence of a conserved transcriptional activation mechanism. Mol.Microbiol. 24: 965-976.

McFall SM, Parsek, MR, Chakrabarty, AM (1997b) 2-Chloromuconate and ClcR-mediated activation of the $c l c A B D$ operon: in vitro transcriptional and DNase I footprint analyses. J. Bacteriol. 179: 3655-3663.

Minh PNL, Ruiz CV, Vandermeeren S, Abwoyo P, Bervoets I and Charlier D (2018) Differential protein-DNA contacts for activation and repression by ArgP, a LysR-type (LTTR) transcriptional regulator in Escherichia coli. Microbiol. Res. 206: 141-158.

Minoda A, Weber APM, Tanaka K and Miyagishima SY (2010) Nucleus-independent control of the rubisco operon by the plastid-encoded transcription factor Ycf30 in the red alga Cyanidioschyzon merolae. Plant Physiol. 154: 1532-1540.

Monferrer D, Tralau T, Kertesz MA, Dix I, Solà M and Usón I (2010) Structural studies on the full-length LysR-type regulator TsaR from Comamonas testosteroni $\mathrm{T}-2$ reveal a novel open conformation of the tetrameric LTTR fold. Mol. Microbiol., 75: 1199-1214.

Moriuchi R, Takada K, Takabayashi M, Yamamoto Y, Shimodaira J, Kuroda N, Akiyama E, Udagawa M, Minai R, Fukuda M, et al., (2017) Amino acid residues critical for DNA binding and inducer recognition in CbnR, a LysR-type transcriptional regulator from Cupriavidus necator NH9. Biosci. Biotechnol. Biochem., 81: 2119-2129.

Mulligan JT and Long SR (1985) Induction of Rhizobium meliloti nodC expression by plant exudate requires nodD. Proc. Natl. Acad. Sci. USA 82: 6609-6613.

Muraoka S, Okumura R, Ogawa N, Nonaka T, Miyashita K and Senda T (2003) Crystal structure of a full-length LysR-type transcriptional regulator, CbnR: Unusual combination of two subunit forms and molecular bases for causing and changing DNA bend. J. Mol. Biol., 328: 555-566.

Nandineni MR and Gowrishankar J (2004) Evidence for an arginine exporter encoded by $y g g A(\arg O)$ that is regulated by the LysR-type transcriptional regulator ArgP in Escherichia coli. J. Bacteriol. 186: 3539-3546.

Ogawa N and Miyashita K (1999) The chlorocatechol-catabolic transposon Tn5707 of Alcaligenes eutrophus NH9, carrying a gene cluster highly homologous to that in the 1,2,4trichlorobenzene-degrading bacterium Pseudomonas sp. strain P51, confers the ability to grow on 3-chlorobenzoate. App. Environ. Microbiol., 65: 724-731.

Ogawa N, McFall SM, Klem TJ, Miyashita K and Chakrabarty A (1999) Transcriptional activation of the chlorocatechol degradative genes of Ralstonia eutropha NH9. J. Bacteriol., 181: 6697-6705.

Parsek MR, McFall SM, Shinabarger DL and Chakrabarty 
AM (1994) Interaction of two LysR-type regulatory proteins CatR and ClcR with heterologous promoters: Functional and evolutionary implications. Proc. Natl. Acad. Sci. USA., 91: 12393-12397.

Park N, Song S, Choi G, Jang KK, Jo I, Choi SH and Ha NC (2017) Crystal structure of the regulatory domain of AphB from Vibrio vulnificus, a virulence gene regulator. Mol. Cells, 40: 299-306.

Parke D (1993) Positive regulation of phenolic catabolism in Agrobacterium tumefaciens by the pcaQ gene in response to $\beta$ -carboxy-cis,cis-muconate. J. Bacteriol. 175: 3529-3535.

Porrúa O, García-Jaramillo M, Santero E and Govantes F (2007) The LysR-type regulator AtzR binding site: DNA sequences involved in activation, repression and cyanuric acid-dependent repositioning. Mol, Microbiol., 66: 410-427

Porrúa O, Platero AI, Santero E, del Solar G and Govantes, F (2010) Complex interplay between the LysR-type regulator AtzR and its binding site mediates atzDEF activation in response to two distinct signals. Mol. Microbiol., 76: 331-347.

Porrúa O, López-Sánchez A, Platero AI, Santero E, Shingler V and Govantes F (2013) An A-tract at the AtzR binding site assists DNA binding, inducer-dependent repositioning and transcriptional activation of the PatzDEF promoter. Mol. Microbiol., 90: 72-87.

Quade N, Dieckmann M, Haffke M, Heroven AK, Dersch P and Heinz DW (2011) Structure of the effector-binding domain of the LysRtype transcription factor RovM from Yersinia pseudotuberculosis. Acta Crystallograph. Sect. D Biol. Cryst., 67: 81-90.

Quitzke V, Fersch J, Seyhan D and Rother M (2018) Seleniumdependent gene expression in Methanococcus maripaludis: Involvement of the transcriptional regulator HrsM. Biochim. Biophys. Acta, 1862: 2441-2450.

Rahav-Manor O, Carmel O, Karpel R, Taglicht D, Glaser G, Schuldiner S, and Padan E (1992) NhaR, a protein homologous to a family of bacterial regulatory proteins (LysR), regulates nhaA, the sodium proton antiporter gene in Escherichia coli. J. Biol. Chem., 267: 10433-10438.

Rivas-Marín E, Floriano B and Santero E (2016) Genetic dissection of independent and cooperative transcriptional activation by the LysR-type activator ThnR at close divergent promoters. Sci. Rep., 6: 10.1038/srep24538.

Rosario CJ, Janes BK, and Bender RA (2010) Genetic analysis of the nitrogen assimilation control protein from Klebsiella pneumoniae. J. Bacteriol., 192: 4834-4846.

Rossen L, Shearman CA, Johnston AW and Downie JA (1985) The nodD gene of Rhizobium leguminosarum is autoregulatory and in the presence of plant exudate induces the $\operatorname{nod} A, B, C$ genes. EMBO J., 4: 3369-3373.

Rothmel RK, Shinabarger DL, Parsek MR, Aldrich TL, and Chakrabarty AM (1991) Functional analysis of the Pseudomonas putida regulatory protein CatR: transcriptional studies and determination of the CatR DNA-binding site by hydroxylradical footprinting. J. Bacteriol., 173: 4717-4724.

Ruangprasert A, Craven S, Neidle E and Momany C (2010) Fulllength structures of BenM and two variants reveal different oligomerization schemes for LysR-type transcriptional regulators. J. Mol. Biol., 404: 568-586.

Russell DA, Byrne GA, O'Connell EP, Boland CA and Meijer WG (2004) The LysR-type transcriptional regulator VirR is required for expression of the virulence gene vapA of Rhodococcus equi ATCC 33701. J. Bacteriol., 186: 5576-5584.

Sainsbury S, Lane LA, Ren J, Gilbert RJ, Saunders NJ, Robinson CV, Stuart DI and Owens RJ (2009) The structure of CrgA from Neisseria meningitides reveals a new octameric assembly state for LysR transcriptional regulators. Nucleic Acids Res., 37: 4545-4558.

Sainsbury S, Ren J, Nettleship JE, Saunders NJ, Stuart DI and Owens RJ (2010) The structure of a reduced form of OxyR from Neisseria meningitides. BMC Struct. Biol., 10: doi: 10.1186/1472-6807-10-10.

Schell MA and Sukhordhaman M (1989) Evidence that the transcription activator encoded by the Pseudomonas putida $n a h R$ gene is evolutionarily related to the transcription activators encoded by the Rhizobium nodD genes. J. Bacteriol., 171: 1952-1959.

Schell MA (1993) Molecular biology of the LysR family of transcriptional regulators. Annu. Rev. Microbiol., 47: 597-626.

Silva IN, Ramires MJ, Azevedo LA, Guerreiro AR, Tavares AC, Becker JD and Moreira LM (2017) Regulator LdhR and D-Lactate Dehydrogenase LdhA of Burkholderia multivorans play roles in carbon overflow and in planktonic cellular aggregate formation. Appl. Environ. Microbiol., https://aem. asm.org/content/83/19/e01343-17

Smirnova IA, Dian C, Leonard GA, McSweeney S, Birse D and Brzezinski P (2004) Development of a bacterial biosensor for nitrotoluenes: The crystal structure of the transcriptional regulator DntR. J. Mol. Biol., 340: 405-418.

Storz G, Tartaglia LA, Ames BN (1990) Transcriptional regulator of oxidative stress-inducible genes: direct activation by oxidation. Science, 248: 189-194.

Stragier P, Richaud F, Borne F and Patte JC (1983) Regulation of diaminopimelate decarboxylase synthesis in Escherichia coli I. Identification of a $l y s R$ gene encoding an activator of the $l y s A$ gene. J. Mol. Biol. 168: 307-320.

Sun J and Klein A (2004) A LysR-type regulator is involved in the negative regulation of genes encoding selenium-free hydrogenases in the archaeon Methanococcus voltae. Mol. Microbiol., 52: 563-571. 
Please cite this article as

Koentjoro and Ogawa, Reviews in Agricultural Science, 6:105-118, 2018 http://dx.doi.org/10.7831/ras.6.105

Taylor JL, De Silva RS, Kovacikova G, Lin W, Taylor RK, Skorupski $\mathrm{K}$ and Kull FJ (2012) The crystal structure of AphB, a virulence gene activator from Vibrio cholerae, reveals residues that influence its response to oxygen and pH. Mol. Microbiol., 83: 457-470.

Toledano MB, Kullik I, Trinh F, Baird PT, Schneider TD and Storz G (1994) Redox-dependent shift of OxyR-DNA contacts along an extended DNA-binding site: A mechanism for differential promoter selection. Cell, 78: 897-909.

Tover A, Zernant J, Chugani SA, Chakrabarty AM and Kivisaar M (2000) Critical nucleotides in the interaction of CatR with the phe $B A$ promoter: conservation of the CatR-mediated regulation mechanisms between the pheBA and catBCA operons. Microbiology, 146: 173-183.

Tralau T, Mampel J, Cook MA, and Ruff J (2003) Characterization of TsaR, an oxygen-sensitive LysR-type regulator for the degradation of $p$-toluenesulfonate in Comamonas testosteroni T-2. Appl. Environ. Microbiol., 69: 2298-2305.

Tyrrell R, Verschueren KH, Dodson EJ, Murshudov GN, Addy C and Wilkinson AJ (1997) The structure of the cofactor-binding fragment of the LysR family member, CysB: A familiar fold with a surprising subunit arrangement. Structure, 5: 1017-1032.

Urbanowski ML, Stauffer LT, Plamann LS, and Stauffer GV (1987) A new methionine locus, metR, that encodes a trans-acting protein required for activation of $m e t E$ and $m e t H$ in Escherichia coli and Salmonella typhimurium. J. Bacteriol., 169: 1391-1397.

van Keulen G, Girbal L, van den Bergh ER, Dijkhuizen L, and Meijer WG (1998) The LysR-type transcriptional regulator CbbR controlling autotrophic $\mathrm{CO}_{2}$ fixation by Xanthobacter flavus is an NADPH sensor. J. Bacteriol., 180: 1411-1417.

van Keulen G, Ridder ANJA, Dijkhuizen L and Meijer WG (2003) Analysis of DNA binding and transcriptional activation by the LysR-type transcriptional regulator CbbR of Xanthobacter flavus. J. Bacteriol., 185: 1245-1252.

Wang L, Helmann JD and Winans SC (1992) The A. tumefaciens transcriptional activator $\mathrm{Occ} R$ causes a bend at a target promoter, which is partially relaxed by a plant tumor metabolite. Cell, 69: 659-667.

Wei Q, Minh PNL, Dötsch A, Hildebrand F, Panmanee W, Elfarash A, Schulz S, Plaisance S, Charlier D, Hassett D, Häussler S, and Cornelis P (2012) Global regulation of gene expression by OxyR in an important human opportunistic pathogen. Nucleic Acids Res., 40: 4320-33.

Wek RC and Hatfield GW (1988) Transcriptional activation at adjacent operators in the divergent-overlapping $i l v Y$ and $i l v C$ promoters of Escherichia coli. J. Mol. Biol., 203: 643-663.

Yen KM and Gunsalus IC (1985) Regulation of naphthalene catabolic genes of plasmid NAH7. J Bacteriol., 162: 1008-1013.

Zaim J and Kierzek AM (2003) The structure of full-length LysR- type transcriptional regulators: Modeling of the full-length OxyR transcription factor dimer. Nucleic Acids Res., 31: 1444-1454.

Zhang Y, Li J, Zhang W, Shi H, Luo F, Hikichi Y, Shi X and Ohnishi K (2018) A putative LysR-type transcriptional regulator PrhO positively regulates the type III secretion system and contributes to the virulence of Ralstonia solanacearum. Mol Plant Pathol., 19: 1808-1819.

Zhou X, Lou Z, Fu S, Yang A, Shen H, Li Z, Feng Y, Bartlam M, Wang H and Rao Z (2010) Crystal structure of ArgP from Mycobacterium tubecolosis confirms two distinct conformations of full-length LysR transcriptional regulators and reveals its function in DNA binding and transcriptional regulation. J. Mol. Biol., 396: 1012-1024. 